\title{
Determination of the boundaries of the sanitary protection zone of the state regional electric power plant: environmental aspect
}

\author{
Olga Mezenina ${ }^{1, *}$ \\ ${ }^{1}$ Ural state forest engineering university, Ekaterinburg, Russia
}

\begin{abstract}
In order to ensure the safety of the population around objects and industries that are sources of impact on the environment and human health, a special territory is established with a special regime of use - the sanitary protection zone (SPZ). According to the regulatory framework of Russia, the approximate size of the SPZ should be justified by the project of a sanitary protection zone with calculations of expected air pollution and levels of physical impact on atmospheric air, and confirmed by the results of field studies and measurements. This paper analyzes the requirements and possibilities for establishing the boundaries of the SPZ for a state regional electric power plant (SREPP). The paper presents an example of the established SPZ boundaries of the energy company, where all calculated indicators correspond to sanitary and construction norms and rules, and the company does not need to create a new SPZ project. The new requirements for defining the SPZ boundaries from 2018 are presented, and terms of object outline, areal object and circuit are analyzed.
\end{abstract}

\section{Introduction}

The sanitary protection zone of any industrial enterprise, in general, is established in order to exclude the harmful effects on the population of adjacent territories of emissions of harmful substances into the atmosphere, industrial noise, electromagnetic fields, as well as to protect the water basin.

Sanitary protection zone is established in order to reduce the level of air pollution, noise levels and other negative impact factors to the maximum permissible values at the border with residential areas due to measures at the SREPP and the organization of planning gaps and landscaping. [1]

The territory of the SPZ is regulated by establishing of the prohibition of the following main types of use: [1]

- placement of residential buildings;

- accommodation of child care and medical institutions;

- placement of sports facilities and parks;

- location of enterprises and warehouses for the production and storage of medicines;

\footnotetext{
*Corresponding author: mob.61@mail.ru
} 
- location of enterprises and warehouses for the production and storage of food and food raw materials;

- placement of wells for drinking water, wells

- growing food.

\section{Methods}

The presence of high sources of heated emissions (chimneys to exhaust flue gases) and dispersed throughout the territory of various organized and unorganized sources of emissions is typical for combined heat and power plant (CHPP) and large boiler houses.

The dimensions of the sanitary protection zone of sources of adverse physical effects are established by calculation, taking into account the location of sources and the nature of the noise, infrasound and other physical factors created by them. The validity of the calculations for establishing the SPZ must be confirmed by field measurements [1].

Depending on the emission characteristics of enterprises, for which the leading factor for determining the size of the sanitary protection zone is chemical pollution of the atmosphere, the position of the SPZ boundary is established from the boundary of the industrial site or from the emission source.

In Russia, the width of the sanitary protection zone is set on the basis of such a calculation that emissions from industrial enterprises that reach residential areas outside it do not exceed the established maximum permissible concentrations (fig.1).

Depending on the degree of harmfulness of industrial emissions emitted into the atmosphere, perfection of technological processes, the availability of treatment facilities, all industrial enterprises are divided into 5 classes with a width of sanitary protection zone for enterprises of the $1^{\text {st }}$ class -1000 meters, $2^{\text {nd }}-500$ meters, $3^{\text {rd }}-300$ meters, $4^{\text {th }}-100$ meters, $5^{\text {th }}-50$ meters $[1,5]$

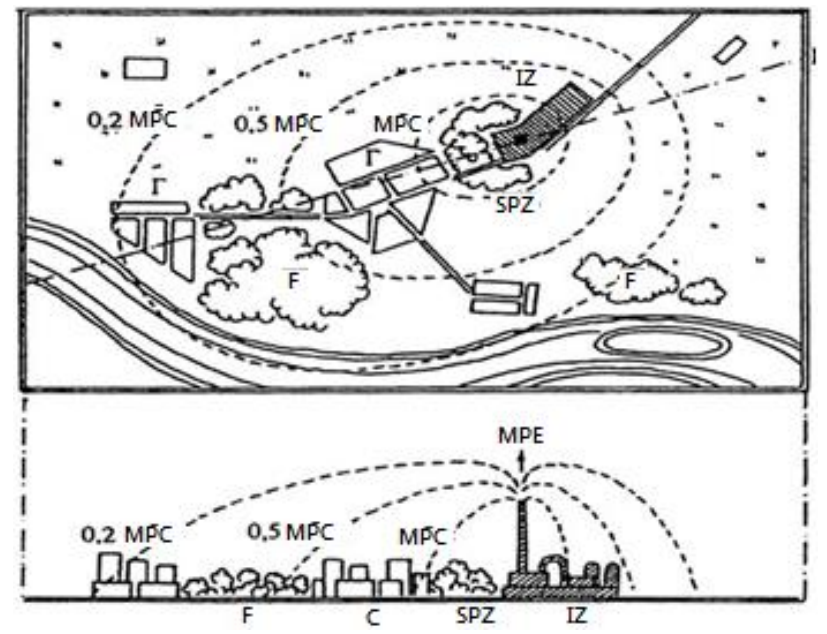

Fig. 1. Layout of the enterprise's SPZ depending on the maximum allowable concentration of chemical elements and their compounds in the environment (MPC).

In our article we will consider this issue on the example of Serovskaya SREPP (branch of Public joint-stock company «Wholesale Generation Company No. 2», which is part of the Serov-Bogoslovsky energy center and is intended for heat and power supply of the city of Serov of the Sverdlovsk region and adjacent areas, as well as for the issuance of electrical power in the network of $110 \mathrm{kV}$ and $220 \mathrm{kV}$ (fig. 2). At the end of 2015, a new power unit of Station No. 9 was put into operation, which replaced the outdated, inefficient 
equipment of the coal part of Serovskaya SREPP, built in the 1950s. In January 2018, the depreciated plant capacity was completely gone out of service. In 2018, as a result of modernization, the installed capacity of the power unit increased to $451 \mathrm{MW}$. Main and backup fuel unit of steam and gas installation (SGI-420) is natural gas. Gas consumption at the prospective part of the SREPP was: in 2015 - 574223 tons of equivalent fuel per year (505,987 million cubic nanometers per year); in 2016-2018 - 610280 tons of equivalent fuel per year (537,759 million cubic nanometers per year) [2-3].

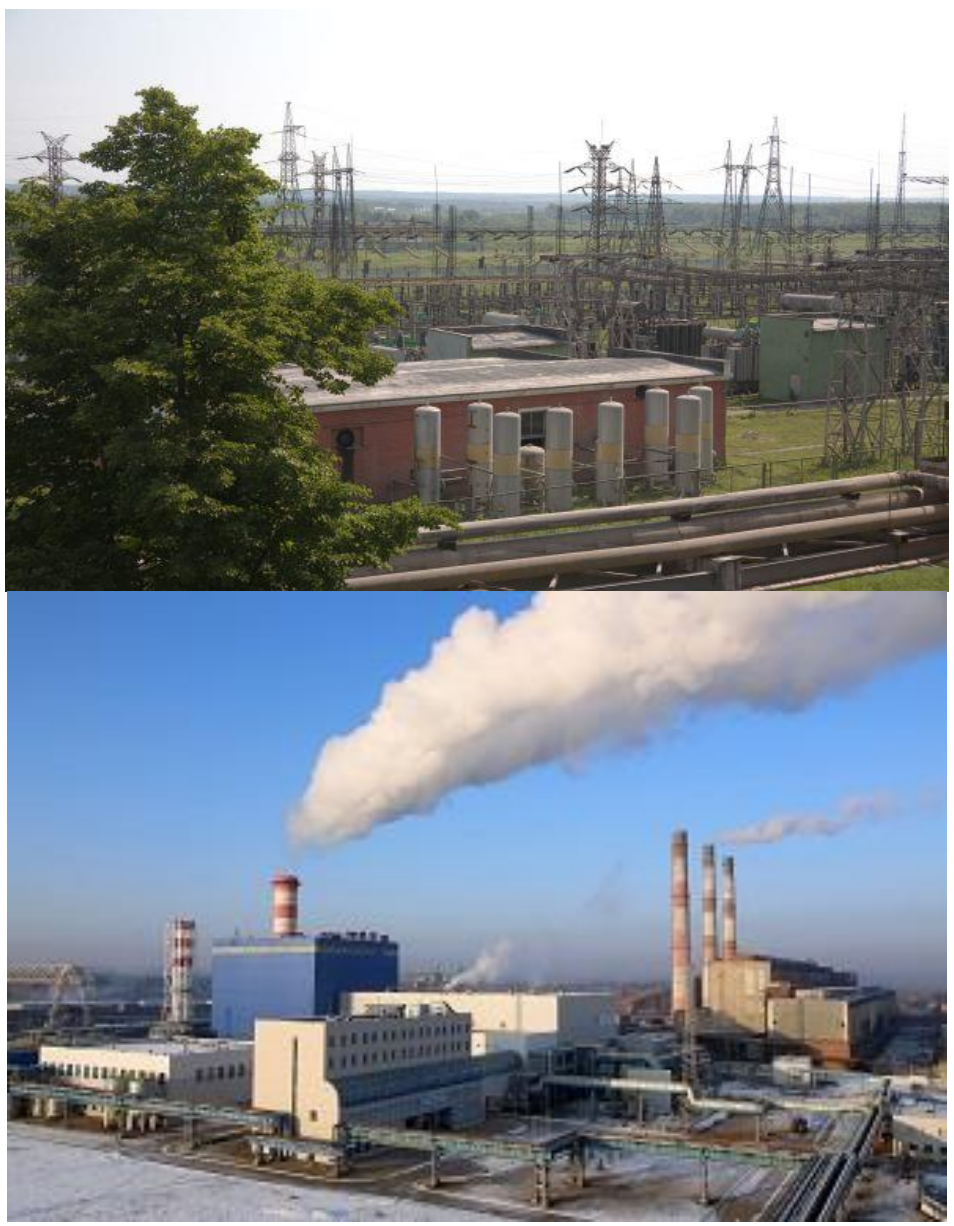

Fig. 2. Serovskaya state regional electric power plant [3].

On the north-west side, in the immediate vicinity of the industrial site of Serovskaya SREPP, there is the village Prisatsionny (the nearest residential buildings are located at a distance of 40-60 meters from its borders) (fig.2).

The nearest settlements in relation to the territory of the state district power station are located as follows:

- in the north-west direction - the settlement Energetikov at a distance of $2 \mathrm{~km}$,

- in the south-west direction - the settlement Novaya Kola at a distance of $2.5 \mathrm{~km}$,

- in the south - the settlement Miners and the village Filkino at a distance of $0.96 \mathrm{~km}$ and $2.24 \mathrm{~km}$. 
- In the north-western direction in the area of the settlement Energetikov there are zones of garden plots. The boundaries of the nearest gardens are located at a distance of $880 \mathrm{~m}$ and $1730 \mathrm{~m}$. [3]

Electricity and heat production at Serovskaya SREPP is carried out using the following main equipment:

- 12 steam boilers of type SB-14 with a steam generating capacity of $230 \mathrm{t} / \mathrm{h}$ each;

- 7 turbine generators with a total capacity of $538 \mathrm{MW}$;

- SGI power unit with a capacity of $420 \mathrm{MW}$ [2-3]

The results of calculations to determine the amount of pollutants emitted into the atmosphere from chimneys during co-combustion of coal and natural gas in boilers are summarized in table 1.

Table 1. The amount of pollutants emitted from chimneys into the atmosphere during co-firing of coal and natural gas in boilers (Serovskaya state regional electric power plant) [2].

\begin{tabular}{|c|c|c|c|}
\hline \multirow{2}{*}{$\begin{array}{l}\text { The name of the } \\
\text { substance }\end{array}$} & \multirow[t]{2}{*}{ Unit of measurement } & \multicolumn{2}{|c|}{ Amount } \\
\hline & & SB-14 & SGI -420 \\
\hline Ash & $t /$ year & 15168.866 & - \\
\hline Metallic mercury & $\mathrm{t} /$ year & 0.012 & - \\
\hline sulphur dioxide & $\mathrm{t} /$ year & 11153.540 & 22.295 \\
\hline Nitrogen dioxide & $t /$ year & 3695.466 & 707.476 \\
\hline Nitrogen oxide & $t /$ year & 600.513 & 114.965 \\
\hline Carbon monoxide & $t /$ year & 334.902 & 530.607 \\
\hline Benzo[a]pyrene & $t /$ year & 0.001 & 0.0005 \\
\hline
\end{tabular}

The sanitary protection zone of any industrial enterprise, in general, is established in order to exclude the harmful effects on the population of adjacent territories of emissions of harmful substances into the atmosphere, industrial noise, electromagnetic fields, as well as to protect the water basin.

According to the Sanitary Regulations and Norms (SanR and N) "Sanitary Protection Zones and Sanitary Classification of Enterprises of Structures and Other Objects" the industrial site of Serovskaya SREPP can be classified as hazard class II objects with an indicative SPZ of $500 \mathrm{~m}$, like «CHPP and regional boiler houses with a heat output of 200 Gcal and more, operating on coal and fuel oil» and « Thermal power plants (TPP) with an equivalent electrical capacity of $600 \mathrm{MW}$ and more, operating on gas fuel oil [4].

The boundaries of the approximate SPZ of the industrial site of Serovskaya SREPP were established from the boundary of the land allotment belonging to the industrial production and the facility for conducting business activities and designed in the prescribed manner, since:

- on the industrial site, in addition to chimneys, there is an open coal storage, fuel and technical oil stores, a motor transport shop, etc., affecting the habitat in the immediate vicinity of the industrial site border within the boundaries of the SPZ;

- the current sanitary regulations do not provide for the possibility of zoning the territory of the industrial site with the definition of the hazard class and size of the indicative SPZ for each production site or facility separately (fig.3) $[3,5]$. 


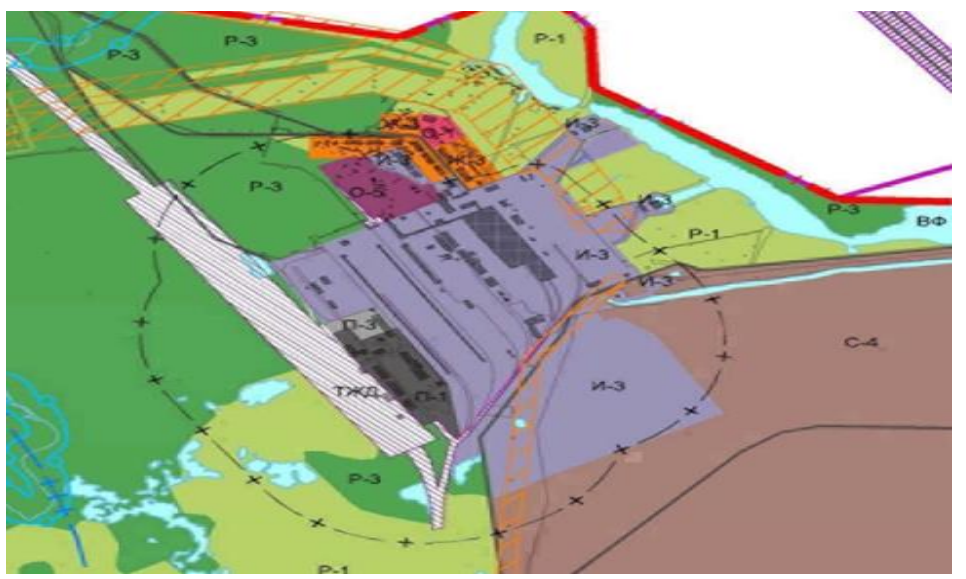

Fig. 3. Serovskaya state regional electric power plant (purple colour, marked И-3) with SPZ borders (dotted line), where dark gray is a zone of hazard class II, marked П-1.

The boundaries of the estimated (preliminary) SPZ of an industrial enterprise are established in stages:

- on the factor of chemical pollution of atmospheric air by calculation;

- on the noise factor by calculation;

- on a factor influence of an electromagnetic field. [1]

Let us present in the work a scheme for determining the boundaries of the SPZ for the industrial site of Serovskaya SREPP.

1) Determination of the boundaries of the SPZ by the factor of chemical pollution of the atmosphere.

According to the analysis of the results of dispersion we draw the following conclusions:

2) Serovskaya SREPP is a source of impact on the environment and human health in terms of air pollution, because total maximum surface concentration of nitrogen dioxide and sulfur dioxide emissions, taking into account background concentrations of more than 0.1 maximum permissible concentration (MPC).

3) maximum surface concentration of emissions of nitrogen dioxide and sulfur dioxide, taking into account the background concentrations $(\mathrm{BC})$ of nitrogen dioxide

$-\Sigma\left\langle\left(\mathrm{NO}_{2}\right)_{\text {SREPP }}+\left(\mathrm{SO}_{2}\right)_{\text {SREPP }}+\left(\mathrm{NO}_{2}\right)_{\mathrm{BC}}\right\rangle=1,22 \mathrm{MPC}$ and does not exceed the allowable (1,6 MPC).

Thus, with the commissioning of power unit No. 9 at Serovskaya SREPP, air pollution by emissions, as we see, does not exceed the permissible norms and does not adversely affect the environment and human health.

On the basis of the presented characteristics, the organization of the sanitary protection zone by the emission factor is not appropriate.

2. Determination of the calculated boundary of the SPZ by the noise factor.

In order to eliminate the impact of noise from the SREPP on a residential area, the construction project of the SGI-420 unit took a number of measures:

- silencer is installed on the intake tract of the integrated air-cleaning device (IACD) of the gas turbine;

- a two-stage silencer is installed at the output of the recovery boiler;

- a decorative lining of the fan cooling tower that performs the functions of a noise shield;

- heat and sound insulation is applied to the surface of the gas-air duct;

- in the gas sector sound absorbing insulation of gas pipelines will be applied; 
- installation of noise suppressors in ducts of air ducts of ventilation systems is supposed; roof silencers on roof fans of the main body.

After the introduction of measures to reduce noise from equipment at Serovskaya SREPP, the following results are assumed:

1) The set of measures to reduce the noise from the equipment included in the delivery set of the expandable part of the Serovskaya GRES will ensure compliance with the established noise level standards for the nearest residential areas at night (45 dB);

2) The noise factor adverse zone is protruding beyond the border of Serovskaya SREPP and does not reach the nearest residential buildings located on the territory of settlement Pristantsionny.

3. Effect on the boundaries of the SPZ effects of the electromagnetic field

The source of the electromagnetic field at Serovskaya SREPP are generators, switchgears, transformers and power lines with a voltage of $110-220 \mathrm{kV}$.

In accordance with the Intersectoral occupational safety rules for the operation of electrical installations (OSR RM-016-2001), the protection of personnel (and personnel of involved organizations when performing repair work) from exposure to the electrical component of the electromagnetic field is not required for electrical installations of $220 \mathrm{kV}$ and below.

Taking into account the fact that the maintenance and repair work of the $220 \mathrm{kV}$ overhead lines located on the territory of the station will be carried out by the employees of the grid organization, the protection of the SREPP employees from the alternating magnetic field is also not required.

In accordance with the "Sanitary norms and rules for the protection of the population from the effects of an electric field generated by overhead power lines of alternating current of industrial frequency» (SanR and N 2971-84), protection of the population from the effects of the electric field of overhead power lines with a voltage of $220 \mathrm{kV}$ and below, meeting the requirements of the Electrical Installation Rules and the High Voltage Electrical Networks Protection Rules, is not required. [1-4]

\section{Results and Discussion}

General conclusions on the determination of the boundaries of the SPZ for the object under study.

According to the results of the study and production calculations, we present the distance from the acoustic center (AC) and from the station boundary to the border of acoustic discomfort in 8 azimuths. Smoke pipe No. 1 was adopted as the acoustic center. In these directions, these distances are presented in Table 2. [2-5]

Table 2. The distance from the acoustic center and from the station boundary to the border of acoustic discomfort in 8 azimuths.

\begin{tabular}{|c|c|c|}
\hline Direction & $\begin{array}{c}\text { Distance from the AC to the } \\
\text { boundaries of the SPZ }\end{array}$ & $\begin{array}{c}\text { The distance from the } \\
\text { station to the boundaries of } \\
\text { the SPZ }\end{array}$ \\
\hline North & 616 & 33 \\
\hline Northwest & 817 & 232 \\
\hline West & 599 & 213 \\
\hline Southwest & 483 & 170 \\
\hline South & 721 & 432 \\
\hline Southeast & 669 & 259 \\
\hline East & 542 & 296 \\
\hline Northeast & 456 & 81 \\
\hline
\end{tabular}


According to the SanR and N 22.1/2.1.1.1200-03 after commissioning of the new Serovskaya SREPP into operation, the calculated parameters should be confirmed by the results of field studies of atmospheric air and measurements of physical impact factors within the framework of supervisory measures and production control data. [1]

In our study, we took the calculations of the dispersion of pollutants in the atmospheric air, made for the winter period of the year, as the most unfavorable, which is associated with maximum loads during the operation of the equipment SREPP.

So, we present the following data provided by the company:

- the maximum surface concentration of nitrogen dioxide emissions will be 0,22 MPC at a distance of $0.94 \mathrm{~km}$ from emission sources;

- the maximum surface concentration of nitrogen oxides will be $0.02 \mathrm{MPC}$ at a distance of $0.94 \mathrm{~km}$ from emission sources;

- the maximum surface carbon dioxide emission concentration is below the calculation criterion (less than 0,01 MPC);

- maximum surface concentration of nitrogen dioxide, taking into account the background concentration of nitrogen dioxide $\left(\mathrm{NO}_{2}+\mathrm{NO}_{2 \mathrm{BC}}\right)=0,22+0,13=0,35 \mathrm{MPC}$;

- maximum surface concentration summation of ingredients $\left(\mathrm{NO}_{2}+\mathrm{SO}_{2}\right)=0,22 \mathrm{MPC}$;

- maximum surface concentration of the summation of ingredients, taking into account the background concentration of nitrogen dioxide $\left(\mathrm{NO}_{2}+\mathrm{SO}_{2}+\mathrm{NO}_{2 \phi}\right)=0,22+0,13=0,35$ MPC.[1-4]

Thus, we see that the maximum surface concentration of all emissions, including the sum of ingredients with regard to the background $(\mathrm{NO} 2+\mathrm{SO} 2)$, will not exceed the MPC. Therefore, the available dimensions of SREPP's SPZ do not require to change. We consider it necessary to note in the article that at present, the Government Decision of 03.03.2018 No. 222 (Decision No. 222) approved the Rules for the establishment of sanitary protection zones and the use of land located within the SPZ. The rules turned the established procedure for determining the need for establishing a SPZ, established for the time being not entirely clear criteria for its necessity, causing many questions. But if the enterprise has already entered data about the enterprise into the unified state register of real estate (USRRE), then the procedure for establishing the SPZ will not be necessary to go through the new requirements again. [1,7]

In the article we present some items that will be added to the existing requirements for the SPZ project for facilities of I and II hazard classes presented in the analysis of Decision No. 222 by the specialists of EKOTIM LLC, A. G. Dudnikova, A. A. Samokhina: explanatory note describing town planning situations (being in close proximity to facilities, buildings, structures), technological process, list of monitored indicators and substances, operation mode of the facility; a map (plan) of a land management object, drawn up in relation to the object's SPZ borders, or a group of objects the procedure for agreeing the boundaries of the SPZ; the boundaries of the zone from point high sources can no longer be set as before from the boiler house pipe - the SPZ will be installed at least from the boiler house building; if the enterprise has two closely located industrial sites, but at the same time the land plots under these industrial sites are not adjacent, then a separate SPZ should be calculated from each industrial site; in terms of measurements, those pollutants will be monitored, the estimated maximum surface concentration of which is more than $0.5 \mathrm{MPC}$ without background. [9]

But the new Decision does not explain how to prove that there are no excesses behind the contour. Determination of control points and impact indicators is established only for measurements carried out as part of production control at the SPZ (after the development of the SPZ project and the establishment of the SPZ boundaries). Decision number 222 applies only to objects, the contour of which sanitary and epidemiological standards are exceeded. How the nature user finds out about this is the business of the nature user. 


\section{Conclusions}

The sanitary protection zone and restrictions on the use of land plots located within its boundaries are considered established from the day the information on such a zone is entered in USRRE. In addition to the project part, you must have a graphic description of the location of the boundaries of the sanitary protection zone (land management plan) with a list of the coordinates of the characteristic points of these boundaries in the coordinate system used USRRE. [7]

An analysis of innovations from 2018 shows that the established procedure for developing a SPZ no longer corresponds to modern realities. Owners of buildings, structures, developers of project documentation should consider the following: from January 1, 2020, the previously established tentative, estimated (preliminary) SPZ shall cease to exist; before October 1, 2019, the owners of buildings and structures for which the tentative, estimated (preliminary) SPZ have been previously determined, must apply to the territorial bodies of Federal Service for Surveillance on Consumer Rights Protection and Human Wellbeing a statement on the establishment of the SPZ or on the termination of the existence of the previously established SPZ; the sanitary protection zone is considered to be established from the date of its introduction into the USRRE. In general, all documentation when developing a SPZ project should be conducted using the USRRE cartographic base and local coordinate system. [6-8]

\section{References}

1. Decision of the Government of the Russian Federation on the approval of the Rules for the establishment of sanitary protection zones and the use of land located within the boundaries of sanitary protection zones, 222 (2018)

2. Official site of the Russian thermal generation company «Wholesale Generation Company No. 2», https://www.ogk2.ru/rus/branch/serovskaya/ (2018)

3. Official website of the Administration of the Serov urban district, http://www.admserov.ru/ (2018)

4. Sanitary Regulations and Norms "Sanitary Protection Zones and Sanitary Classification of Enterprises of Structures and Other Objects" 2.2.1/2.1.1.1200-03 (2014)

5. Decision of the Government of the Russian Federation, On approval of the form of a map (plan) of a land management facility and requirements for its compilation, 621 (2009)

6. Federal Law, On Amendments to the Urban Planning Code of the Russian Federation and certain legislative acts of the Russian Federation, 342 (2018)

7. Federal Law, On State Registration of Real Estate, 218 (2015)

8. Federal Law, On Amendments to the Urban Planning Code of the Russian Federation and certain legislative acts of the Russian Federation, 340 (2018)

9. G. Dudnikova, A.A. Samokhina, The Necessity of Establishing the SPZ. Analysis of draft by-laws, electronic version of the scientific and practical journal "Ecology of Production", ecoindustry.ru (2018) 